\title{
Sex matters: secular and geographical trends in sex differences in coronary heart disease mortality
}

\author{
D A Lawlor, S Ebrahim, G Davey Smith
}

\begin{abstract}
Objective To examine secular trends and geographical variations in sex differences in mortality from coronary heart disease and investigate how these relate to distributions in risk factors.

Design National and international data were used to examine secular trends and geographical variations in sex differences in mortality from coronary heart disease and risk factors.

Setting England and Wales, 1921-98; Australia, France, Japan, Sweden, and the United States, 1947-97; 50 countries, 1992-6.

Data sources Office for National Statistics, World Health Organization, and Food and Agriculture Organization of the United Nations.

Results The 20th century epidemic of coronary heart disease affected only men in most industrialised countries and had a very rapid onset in England and Wales, which has been examined in detail. If this male only epidemic had not occurred there would have been 1.2 million fewer deaths from coronary heart disease in men in England and Wales over the past 50 years. Secular trends in mean per capita fat consumption show a similar pattern to secular trends in coronary heart disease mortality in men. Fat consumption is positively correlated with coronary heart disease mortality in men $\left(r_{\mathrm{s}}=0.79 ; 95 \%\right.$ confidence interval 0.70 to 0.86 ) and inversely associated with coronary heart disease mortality in women $(-0.30 ;-0.49$ to -0.08$)$ over this time. Although sex ratios for mortality from coronary heart disease show a clear period effect, those for lung cancer show a cohort effect. Sex ratios for stroke mortality were constant and close to unity for the entire period. Geographical variations in the sex ratio for coronary heart disease were associated with mean per capita fat consumption $(0.64 ; 0.44$ to 0.78$)$ but were not associated with the sex ratio for smoking. Conclusion Sex differences are largely the result of environmental factors and hence not inevitable. Understanding the factors that determine sex differences has important implications for public health, particularly for countries and parts of countries where the death rates for coronary heart disease are currently increasing.
\end{abstract}

\section{Introduction}

It is well known that there is a sex difference in mortality from coronary heart disease; the reason for this difference is widely assumed to be due to the protective effect of oestrogen. However, trials in the 1960s and 1970s to prevent coronary heart disease in men by giving them high doses of oestrogen had unfavourable results. ${ }^{1}$ If environmental factors play a part in the sex difference in the occurrence of coronary heart disease then it may be possible to reduce mortality in men to levels similar to those found in women.
Few studies have looked at secular trends in the sex difference in mortality in coronary heart disease despite the obvious potential for such analyses to provide valuable insights into this phenomenon. In this study we examine secular and geographical trends in the sex ratio for coronary heart disease mortality and other related conditions and compare these to trends in distributions in risk factors.

\section{Methods}

\section{Secular trends}

We used Office for National Statistics data to examine secular trends from 1921-98 in mortality for coronary heart disease and other conditions that coronary heart disease may have been misdiagnosed as-stroke, other circulatory disease, renal disease, respiratory disease, and ill-defined mortality-in men and women aged 34 to 75 , in England and Wales. In addition, we assessed secular trends in sex ratios for mortality from lung cancer from 1940, when lung cancer was first included in International Classification of Diseases (ICD) codes. Total mean per capita proportion of energy derived from fat and total mean per capita alcohol consumption for the United Kingdom over the period 1921-97 were obtained from published sources. ${ }^{2-5}$

We used World Health Organization (WHO) data to analyse secular trends in mortality from coronary heart disease in men and women from Australia, France, Japan, Sweden, and the United States from 1947 to 1997.

\section{Geographical variations}

We used WHO data to calculate the sex ratio of mortality from coronary heart disease and lung cancer using age standardised five year aggregate death rates (1992-6) for 50 countries. For each country we calculated a five year aggregate (1992-6) mean daily per capita total energy derived from fat using data from the Food and Agriculture Organization (FAO) of the United Nations. ${ }^{6}$ Sex specific smoking prevalence for a single year only (1990) and for European countries only was obtained from the WHO.

\section{Accuracy and completeness of mortality data}

Between $95 \%$ and $100 \%$ of the deaths for all of the data examined in this study had been certified. In addition, for all countries over all time periods the proportion of deaths attributed to the diagnostic category "signs and symptoms and other ill defined conditions" was less than $5 \%$ and did not differ between the sexes. The only exception was Brazil, where over $16 \%$ of deaths were for ill defined conditions. However, this did not vary between men and women, and excluding data from Brazil from the analyses did not affect any of the outcomes.

\section{Statistical analysis}

All rates were age standardised by the direct method weighted to the WHO European standard population.

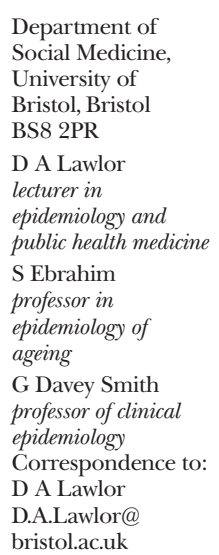

BMJ 2001;323:541-5

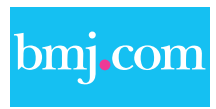

Full details of all data sources and ICD codes are provided on the $B M J$ 's website 
Regression modelling was used to determine the year in which there was a significant change in observed trends. ${ }^{7}$ Spearman's rank correlation coefficient $\left(r_{\mathrm{s}}\right)$ was used to assess associations between sex ratios and risk factor distributions. All analyses used Stata version 6.0.

Full details of all data sources and ICD codes are provided on the $B M$ /s sebsite. For all analyses ICD codes recommended in a recent review of mortality trends were used to define the cause of death. ${ }^{8}$

\section{Results}

\section{Secular trends}

From 1921 to 1949, in England and Wales, coronary heart disease mortality was higher in men than in women but the pattern of change was similar in both. From 1949 the trends diverged, with a marked increase in men, peaking in the early 1970 s. Rates in women over the same time period were stable or declined (fig $1)$. These changes resulted in an increase in the sex ratio from a constant value of 1.5 between 1921 and 1949 to a peak of 3.5 in 1972 (fig 2). This change began in the same year (1949) in all age groups (fig 3). If the sex ratio had remained at 1.5 and rates for women stayed as they were for the whole period, 1.2 million fewer deaths would have occurred in men between 1949 and 1998.

Secular trends in mean per capita fat consumption for the period showed a similar pattern to those for male mortality and hence the sex ratio in mortality from coronary heart disease (fig 2). Mean per capita fat consumption was strongly positively correlated with the sex ratio for coronary heart disease mortality $\left(r_{\mathrm{s}}=0.89,95 \%\right.$ confidence interval 0.83 to 0.93 , $\mathrm{P}<0.01)$ and to mortality in men $(0.79,0.70$ to 0.86 , $\mathrm{P}<0.01)$ over this period and inversely correlated to mortality in women $(-0.30,-0.49$ to $-0.06, \mathrm{P}=0.01)$. The calculations incorporating the assumption that there is a 10 year lag in the effect of dietary fat on coronary heart disease $\mathrm{e}^{9}$ slightly strengthen the correlation between fat consumption and the sex ratio in coronary heart disease mortality to $0.96(0.94$ to $0.98, \mathrm{P}<0.01)$.

Mean per capita alcohol consumption was correlated with the sex ratio in mortality from coronary heart disease over this period $(0.51,0.32$ to 0.66 , $\mathrm{P}<0.01$ ); it was weakly positively correlated with male

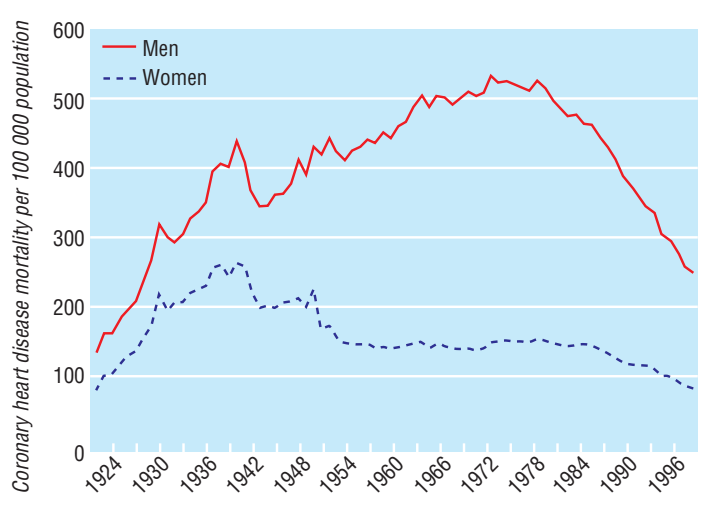

Fig 1 Secular trends in age standardised mortality per 100000 population from coronary heart disease for men and women, 1921-98, England and Wales

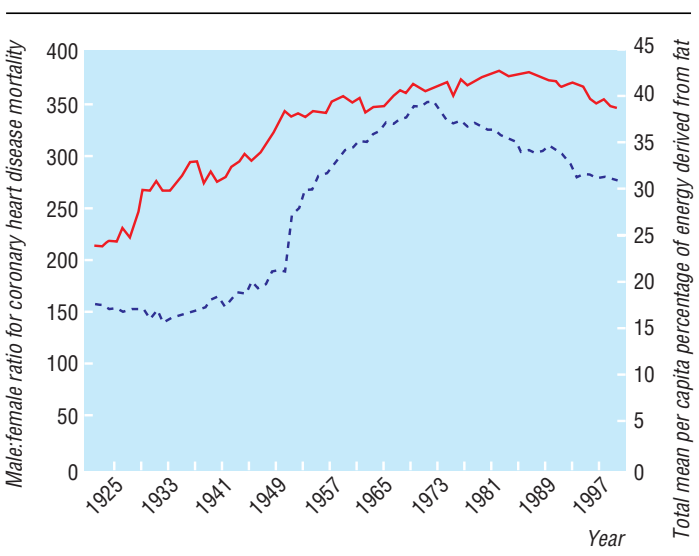

Fig 2 Secular trends in male:female ratio (expressed as a percentage; solid line) for age standardised mortality from coronary heart disease and in mean per capita percentage of energy derived from fat (broken line), 1921-98, United Kingdom

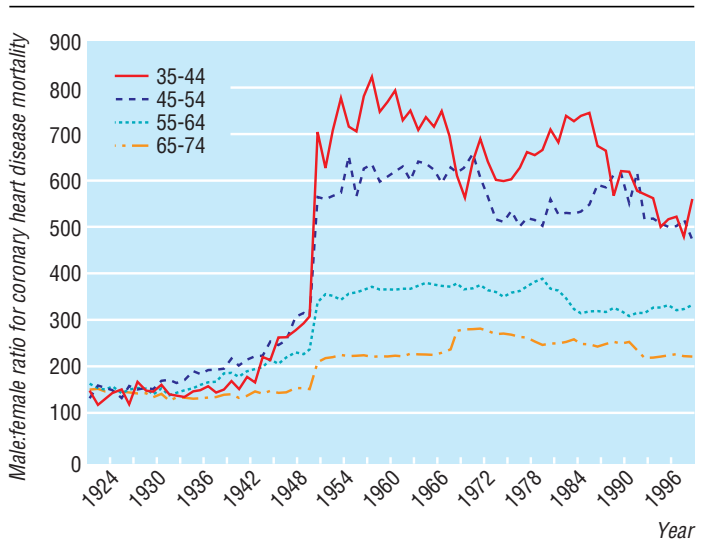

Fig 3 Secular trends in male:female ratio (expressed as a percentage) for mortality from coronary heart disease for different generations in 10 year age bands, 1921-98, England and Wales

mortality from coronary heart disease and inversely correlated with female mortality from coronary heart disease $(0.25,0.03$ to $0.45, \mathrm{P}=0.04 ;-0.49,-0.64$ to $-0.30, \mathrm{P}<0.01$, respectively).

For lung cancer the sex ratio showed a clear cohort effect, with the peak occurring in later years for each successively older cohort (fig 4). Death rates for stroke decreased in both men and women over the entire period with the sex ratio remaining around unity for the period. There was no corresponding increase in death rates in women or decrease in the sex ratios for any of the diagnostic categories to which misdiagnosed coronary heart disease deaths could possibly have been assigned.

Similar trends in mortality from coronary heart disease were seen in Australia, France, Sweden, and the United States (fig 5). Trends for Japanese men and women were similar (fig 5), although the increase in rates was greater for men so that the sex ratio increased from 1.2 in 1947 to 2.8 by the late 1980 s. The sharp drop in coronary heart disease rates for Japanese men and women in the late 1960 s corresponded to a change in ICD coding practice. 


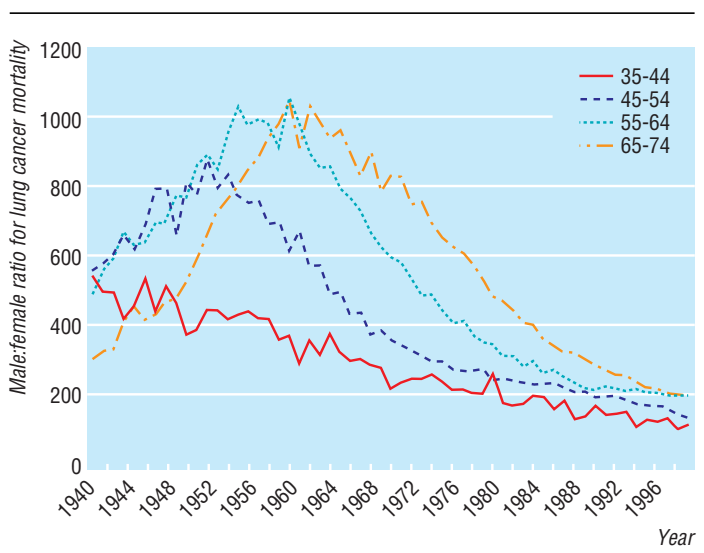

Fig 4 Secular trends in male:female ratio (expressed as a percentage) for lung cancer mortality for different generations in 10 year age bands, 1940-98, England and Wales
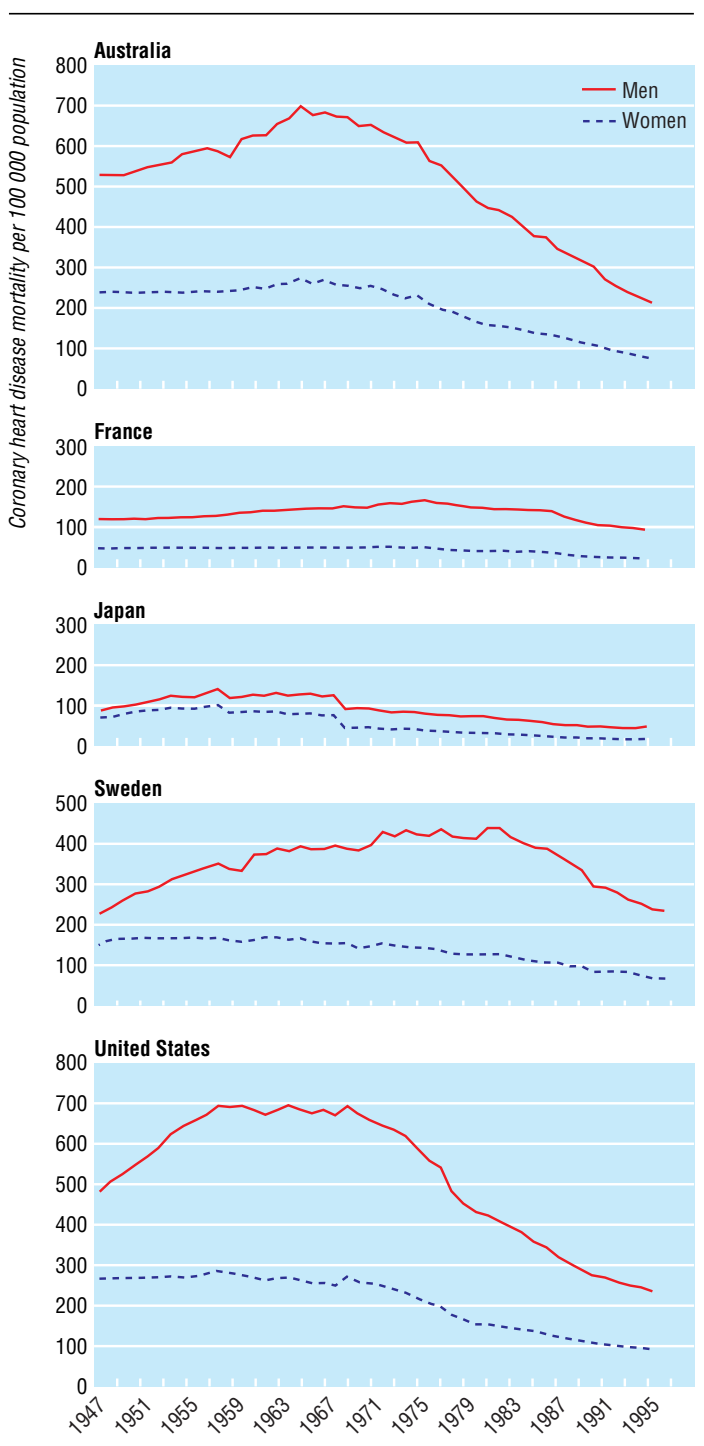

Fig 5 Secular trends in age standardised mortality per 100000 population from coronary heart disease for men and women, 1947-97, Australia, France, Japan, Sweden, United States

Year

\section{Geographical trends}

Across the 50 countries considered, the sex ratio for mortality from coronary heart disease ranged from 1.4 to 2.9 (table). The highest ratios were seen in Poland, France, and Norway and the lowest in rural China, Cuba, and Armenia. The sex ratio for mortality from coronary heart disease was positively associated with mean per capita fat consumption $(0.64,0.44$ to 0.78 , $\mathrm{P}<0.01$ ) but was not associated with either the sex ratio for lung cancer mortality or the sex ratio for smoking prevalence. The sex ratio for lung cancer was associated with the sex ratio for smoking prevalence $(0.49,0.09$ to $0.67, \mathrm{P}=0.01)$.

\section{Discussion}

The sex difference in mortality from coronary heart disease varies over time and geographically-the 20th century epidemic of coronary heart disease affected only men in England and Wales and other industrialised countries. A protective effect of oestrogen alone cannot explain these trends because it is inconceivable that levels of oestrogen in women have changed dramatically over the past century or vary greatly among women of different countries. Indeed, the dramatic "period effect" seen in the secular trends in the sex ratio for mortality from coronary heart disease suggests an environmental impact that affects only men and occurred before the late 1940s.

\section{Artifact as a possible explanation}

Secular trends may be affected by changes in coding practice, diagnostic fashion, and increased survival of the population. ${ }^{10}$ Changes in coding practice and increased survival should affect men and women in the same way and would therefore not explain changes in the sex ratio. Our data show that trends in male and female mortality from coronary heart disease mirrored each other between 1921 and 1949, during which time there were three ICD changes. We could find no compensatory change in death rates in any other causes of death to which women with coronary heart disease could plausibly be misdiagnosed. The population denominators used in this study have changed over time. In particular, during both world wars the populations referred to civilian populations only and had a lower proportion of healthy individuals. ${ }^{11}$ The changes in population denominators for the war period affected both sexes in the same way and therefore cannot explain the sex differences in secular trends. ${ }^{11}$ By using death rates that were age standardised we have adjusted for the changing age distribution of the population.

Our findings largely agree with previous studies, which found a rising male to female sex ratio for total heart disease mortality from the 1950 s to the 1980 s in several industrialised countries. ${ }^{12}{ }^{13}$ In the United States the rise in the sex ratio for heart disease mortality began earlier-that is, in the $1920 \mathrm{~s}^{14}{ }^{15}$ None of these studies attempt to explain why the risk of heart disease mortality in men should have increased over time and differently between places.

Sex differences in effect or distribution of known risk factors

The level of risk for smoking, hypertension, and cholesterol-the major risk factors for coronary heart 
Male:female mortality ratios for coronary heart disease and lung cancer, sex ratio of smoking prevalence, and total mean per capita fat consumption for different countries

\begin{tabular}{|c|c|c|c|c|}
\hline \multirow[b]{2}{*}{ Country } & \multicolumn{3}{|c|}{ Male:female ratio } & \multirow[b]{2}{*}{$\begin{array}{l}\text { \% of energy } \\
\text { derived from fat }\end{array}$} \\
\hline & $\begin{array}{l}\text { Coronary heart } \\
\text { disease mortality }\end{array}$ & $\begin{array}{l}\text { Lung cancer } \\
\text { mortality }\end{array}$ & $\begin{array}{l}\text { Prevalence of } \\
\text { smoking }^{*}\end{array}$ & \\
\hline China, rural & 1.4 & 2.6 & - & 21 \\
\hline Cuba & 1.4 & 2.7 & - & 19 \\
\hline Armenia & 1.5 & 7.2 & - & 17 \\
\hline Republic of Moldova & 1.5 & 10.0 & - & 19 \\
\hline Costa Rica & 1.6 & 2.7 & - & \\
\hline Azerbaijan & 1.7 & 6.1 & - & 15 \\
\hline Belarus & 1.7 & 13.7 & 10.6 & 27 \\
\hline Brazil & 1.7 & 3.3 & - & 26 \\
\hline Hong Kong & 1.7 & 4.4 & - & \\
\hline Israel & 1.7 & 6.9 & 1.2 & 33 \\
\hline Romania & 1.7 & 8.6 & 3.3 & 24 \\
\hline Bulgaria & 1.8 & 5.8 & 2.4 & 30 \\
\hline Croatia & 1.8 & 7.5 & - & 27 \\
\hline Kyrgyzstan & 1.8 & 10.1 & - & 20 \\
\hline Lithuania & 1.8 & 4.7 & - & 24 \\
\hline Slovak Republic & 1.8 & 1.9 & 1.9 & 32 \\
\hline China, urban & 1.9 & 2.3 & - & 21 \\
\hline Czech Republic & 1.9 & 5.9 & 1.7 & 32 \\
\hline Japan & 1.9 & 7.2 & - & 25 \\
\hline Kazakhstan & 1.9 & 6.2 & - & 22 \\
\hline USA & 1.9 & 2.0 & - & 35 \\
\hline Australia & 2.0 & 2.9 & - & 37 \\
\hline Denmark & 2.0 & 1.8 & 1.1 & 37 \\
\hline Estonia & 2.0 & 7.2 & 2.2 & 28 \\
\hline Hungary & 2.0 & 2.5 & - & 37 \\
\hline Slovenia & 2.0 & 6.2 & 1.5 & 31 \\
\hline Austria & 2.1 & 4.1 & 6.3 & 41 \\
\hline$\overline{\text { Canada }}$ & 2.1 & 2.2 & - & 37 \\
\hline Germany & 2.1 & 7.0 & 1.7 & 38 \\
\hline New Zealand & 2.1 & 2.6 & - & 36 \\
\hline Northern Ireland & 2.1 & 6.4 & 1.2 & 39 \\
\hline Portugal & 2.1 & 7.1 & 4.3 & 32 \\
\hline Republic of Korea & 2.1 & 6.1 & - & 22 \\
\hline Russian Federation & 2.1 & 6.7 & 4.4 & 25 \\
\hline Scotland & 2.1 & 12.9 & 1.1 & 39 \\
\hline England and Wales & 2.2 & 9.4 & 1.0 & 39 \\
\hline Ireland & 2.2 & 3.1 & 1.0 & 33 \\
\hline Italy & 2.2 & 3.7 & 1.9 & 38 \\
\hline Belgium & 2.3 & 7.7 & 1.4 & 40 \\
\hline Finland & 2.3 & 7.7 & 1.5 & 37 \\
\hline Latvia & 2.3 & 11.5 & 4.5 & 26 \\
\hline Sweden & 2.3 & 2.5 & 0.8 & 37 \\
\hline Macedonia & 2.3 & 2.2 & - & 24 \\
\hline Argentina & 2.4 & 5.8 & - & 33 \\
\hline Greece & 2.4 & 2.3 & 1.6 & 37 \\
\hline Netherlands & 2.4 & 2.2 & 1.2 & 39 \\
\hline Spain & 2.4 & 2.4 & 1.7 & 39 \\
\hline Norway & 2.5 & 6.4 & 1.1 & 37 \\
\hline France & 2.6 & 5.0 & 1.7 & 42 \\
\hline Poland & 2.9 & 4.2 & 1.8 & 30 \\
\hline
\end{tabular}

All data represent five year aggregate (1992-6) except sex ratio for smoking prevalence, which is based on data from 1990 only.

${ }^{*}$ Smoking data available only for European countries.

disease -is the same for men and women. ${ }^{16}$ Changes in sex differences in smoking behaviour in the United States over the past 30 years predict secular trends in sex differences in lung cancer; they do not predict changes in sex differences for coronary heart disease. ${ }^{17}$ Our analyses over a longer period concur with these results. The secular trends in the coronary heart disease sex ratio suggest an exposure with a differential impact affecting all generations at the same time- that is, a period effect. This contrasts with the pattern for lung cancer, where the cohort effect suggests effects influencing successive generations throughout their lives-the uptake of smoking is the obvious exposure. If the observed trends for sex ratio for coronary heart disease were due to sex differences in smoking distribution we would expect to find a cohort relationship similar to that seen for lung cancer, which is undeniably caused by smoking. Furthermore, geographical variation in sex ratios for coronary heart disease is not associated with sex ratios in prevalence of lung cancer or smoking. Although it is abundantly clear that cigarette smoking is an important determinant of male or female individual susceptibility to coronary heart disease, our findings show that a sex difference in smoking rates is not the explanation for the sex difference in coronary heart disease. Sex differences in hypertension over time or between countries cannot explain the sex differences in coronary heart disease as there are no sex differences in stroke mortality, which is clearly influenced by hypertension. Age adjusted mean cholesterol concentrations do not differ between men and women in the WHO MONICA (monitoring trends and determinants in cardiovascular disease) study centres ${ }^{18}$ and in the United States have not differed over time between the sexes since the 1960s. ${ }^{19}$

\section{Alcohol consumption}

The relation between mean alcohol consumption and coronary heart disease risk is J shaped in both men and women and there is evidence that drinking pattern is also important in coronary heart disease, with binge drinking being harmful. ${ }^{20}$ It is possible that our secular trend results reflect different drinking patterns between men and women, with mean per capita increases reflecting an increase of binge drinking in men. This is unlikely, however, as there was no similar change in the sex difference in stroke mortality over this period.

\section{Food consumption}

Both secular and geographical trends in the sex ratio are strongly correlated to total mean per capita fat consumption. This implies either that dietary fat intake differs between men and women or that women and men differ in their response to dietary fat. A differential response between men and women to dietary fat has been suggested. Evidence from randomised controlled trials shows that the concentration of high density lipoprotein cholesterol is increased in women more readily than in men in response to diets high in saturated fat, and it is reduced with low fat diets to a greater extent in women than men. ${ }^{21}{ }^{22}$ Recent studies have shown that atherogenic lipid profiles are associated with increased risk of ischaemic, but not haemorrhagic, strokes. ${ }^{23} \mathrm{~A}$ change over time in the sex difference in ischaemic stroke mortality may not be discernible in our study, which, when routine data are used, is unable to distinguish between types of strokes. Further studies are required to assess whether there is indeed a differential response to dietary fat between women and men.

UK and US food surveys going back as far as the 1930s show that there was no significant difference between men and women in total dietary fat consumption. $^{2}{ }^{24}$ There may, however, have been sex differences in the types of fat consumed. During and immediately after the second world war, meat was rationed in Britain. Whale meat and a form of dried fish called snoek 
were imported from Scandinavia as an alternative; both were found to be unpalatable. ${ }^{25}$ It is probable that women would have consumed more of these, with the scarcer red meat being reserved for men. Historical reports covering the United Kingdom and other European countries have shown that food consumption was differentiated within families along the lines of age and sex at this time, with men in general being given more meat. ${ }^{26} 27$ Cultural differences in perceptions of what types of food are considered to be the best might explain why secular trends in mortality from coronary heart disease between Japanese women and men are more closely matched.

War as an explanation for these trends

Feinleib suggested that because the male epidemic in coronary heart disease began in the 1920s in the United States, factors associated with the first world war may have been responsible for the increased mortality from coronary heart disease in men. ${ }^{15}$ In our data for the United Kingdom, the divergence begins shortly after the second world war. Large numbers of the fittest men may have been lost in conflict, with the result that rates of coronary heart disease were higher in the less fit men who remained. Although there is no direct evidence that war leads to greater depression in men than women, it has been shown that depression is associated with an increased risk of coronary heart disease. ${ }^{28}$ War is an unlikely explanation for the secular trends because mortality from coronary heart disease in men continued to increase in both the United States and the United Kingdom for over 20 years after the end of the conflicts and increased in men of all ages. Conflict cannot explain geographic variations in the sex difference of mortality from coronary heart disease.

\section{Conclusion}

Secular and geographical trends indicate that a protective effect of endogenous oestrogen does not explain the sex difference in occurrence of coronary heart disease and that environmental factors are important. Identification of the factors responsible for sex differences in occurrence of coronary heart disease could importantly inform preventive strategies, particularly in countries or parts of countries where rates of coronary heart disease are currently increasing.

Contributors: All authors designed the study and formulated the hypotheses. DAL retrieved data, undertook the analysis, and wrote the initial draft of the paper. All authors contributed to the final paper and all act as guarantors.

Funding: None.

Competing interests: None declared.

1 Coronary Drug Project Research Group. The coronary drug project. Findings leading to discontinuation of the $2.5-\mathrm{mg}$ day estrogen group. JAMA 1973;226:652-7.

2 Stephen AM, Sieber GM. Trends in individual fat consumption in the UK 1900-1985. Br J Nutr 1994;71:775-88.

3 Petersen S, Mockford C, Rayner M. Coronary heart disease statistics. British Heart Foundation statistics database 1999. London: British Heart Foundation, 1999

4 Advisory Panel on Diet in relation to Cardiovascular and Cerebrovascular Disease. Diet and coronary heart disease. London: HMSO, 1974.

5 Plant M. Trends in alcohol and illicit drug-related diseases. In: Charlton J, Murphy M, eds. The health of adult Britain 1841-1994. London: Stationer Office, 1997:114-27.

6 Sasaki S, Kesteloot H. Value of Food and Agriculture Organization data on food-balance sheets as a data source for dietary fat intake in epidemiologic studies. Am J Clin Nutr 1992;56:716-23.

\section{What is already known on this topic}

Mortality for coronary heart disease is greater in men than women in most industrialised countries

The most widely accepted explanation for this difference is that women are protected by oestrogen

\section{What this study adds}

The sex difference in mortality from coronary heart disease varies over time and between countries in a way that cannot be explained by endogenous oestrogen

These trends indicate that sex differences in mortality from coronary heart disease are driven primarily by environmental factors

Sex differences in coronary heart disease are not inevitable

Understanding more about the factors that cause the sex differences in mortality from coronary heart disease has important public health implications

Kim HJ, Fay MP, Feuer EJ, Midthune DN. Permutation tests for joinpoint regression with applications to cancer rates. Stat Med 2000;19:335-51.

8 Charlton J, Murphy M. The health of adult Britain 1841-1994. London: Stationery Office, 1997.

9 Stamler J. Opportunities and pitfalls in international comparisons related to patterns, trends and determinants of CHD mortality. Int J Epidemiol 1989:18:S3-18.

10 Stehbens WE. An appraisal of the epidemic rise of coronary heart disease and its decline. Lancet 1987;i:606-11.

11 Charlton J. Trends in all cause mortality: 1841-1994. In: Charlton J, Murphy M, eds. The health of adult Britain: 1841-1994. London: Stationery Office, 1997:17-29.

12 Zhang XH, Sasaki S, Kesteloot $\mathrm{H}$. The sex ratio of mortality and its secular trends. Int J Epidemiol 1995;24:720-9.

13 Uemura K, Pisa Z. Trends in cardiovascular disease mortality in industrialized countries since 1950. World Health Stat Q 1988;41:155-78.

14 Anderson TW. Mortality from ischemic heart disease. Changes in middle-aged men since 1900. JAMA 1973;224:336-8.

15 Feinleib M. Trends in heart disease in the United States. Am J Med Sci 1995;310(suppl 1):S8-14.

16 Isles CG, Hole DJ, Hawthorne VM, Lever AF. Relation between coronary risk and coronary mortality in women of the Renfrew and Paisley survey: comparison with men. Lancet 1992;339:702-6.

17 Waldron I. Recent trends in sex mortality ratios for adults in developed countries. Soc Sci Med 1993;36:451-62.

18 Kuulasmaa K, Tunstall-Pedoe H, Dobson A, Fortmann S, Sans S, Tolonen $\mathrm{H}$, et al. Estimation of contribution of changes in classic risk factors to trends in coronary-event rates across the WHO MONICA project populations. Lancet 2000;355:675-87

19 Posner BM, Franz MM, Quatromoni PA, Gagnon DR, Sytkowski PA, D'Agostino RB, et al. Secular trends in diet and risk factors for cardiovascular disease: the Framingham Study. J Am Diet Assoc 1995;95:171-9.

20 Britton A, McKee M. The relation between alcohol and cardiovascula disease in Eastern Europe: explaining the paradox. J Epidemiol Community Health 2000;54:328-32.

21 Clifton PM, Nestel PJ. Influence of gender, body mass index, and age on response of plasma lipids to dietary fat plus cholesterol. Arterioscle Thromb 1992;12:955-62.

22 Walden CE, Retzlaff BM, Buck BL, McCann BS, Knopp RH. Lipoprotein lipid response to the national cholesterol education program step II diet by hypercholesterolemic and combined hyperlipidemic women and men. Arterioscler Thromb Vasc Biol 1997; 17:375-82.

23 Hart CL, Hole DJ, Smith GD. The relation between cholesterol and haemorrhagic or ischaemic stroke in the Renfrew/Paisley study. J Epidemiol Community Health 2000;54:874-5.

24 Stephen AM, Wald NJ. Trends in individual consumption of dietary fat in the United States, 1920-1984. Am J Clin Nutr 1990;52:457-69.

25 Cooper S. Snoek piquante. The trials and tribulations of the British housewife. In: Siaaons, M, French P, eds. Age of austerity 1945-51. Oxford: Oxford University Press, 1986:34-57.

26 Charles N, Kerr M. Women, food and families. Manchester: Manchester University Press, 1997.

27 Oren L. The welfare of women in labouring families: England, 1860-1950. In: Hartman MS, Banner L, eds. Clio's consciousness raised:new perspectives on the history of women. London: Harper and Row, 1974:226-44.

28 Hemingway H, Marmot M. Evidence based cardiology: psychosocial factors in the aetiology and prognosis of coronary heart disease. Systematic review of prospective cohort studies. BMJ 1999;318:1460-7.

(Accepted 17 May 2001) 